Preprint of the published article: Felicitas Macgilchrist (2019) Cruel optimism in edtech: when the digital data practices of educational technology providers inadvertently hinder educational equity, Learning, Media and Technology, 44:1, 77-86, DOI: 10.1080/17439884.2018.1556217

\title{
Cruel optimism in edtech: When the digital data practices of educational technology providers inadvertently hinder educational equity
}

\section{Felicitas Macgilchrist}

Media|Transformation Department, Georg Eckert Institute for International Textbook Research, Braunschweig, Germany; Institute for Educational Science, University of Goettingen, Goettingen, Germany. Email: macgilchrist@ leibniz-gei.de; Twitter: @ discoursology.

As digital data become increasingly central to education, hopes for educational equity are pinned more strongly on educational technology providers. This paper examines the data practices of edtech providers who are not simply making token gestures towards justice and equality. Drawing on ethnographic interviews and Berlant's notion of cruel optimism, it presents three data stories. The paper suggests that datafication in education provides a showcase of cruel optimism, i.e., when the object of desire is blocking one's flourishing. The conclusion considers the constitutive paradoxes of datafied education, and implications for education in the current phase of edu-technical transformation.

Keywords: educational technology, datafication, data practices, inequality, ethnography

'[E]veryone needs enhanced digital skills to participate fully in society' (European Commission 2014: 3; see also Working Group 2017: 15). Governments and philanthropists worldwide strive to provide access to technology in the belief that overcoming what has been called the 'digital divide' will ameliorate disadvantage and increase educational equity. Yet it is evident that the way digital technology is used today is (perhaps inadvertently) strengthening existing socio-economic inequalities. Studies on technological change and social inequality have identified correlations between differential access, usage, attitudes, skills, discourses, structures, and infrastructures and a range of individual and societal domains, including life chances, civic engagement, health care, political activism, health behaviour, entrepreneurship, social capital, age, education, disability, gender, 'race' and class (ITU 2017a, 2017b; Robinson et al. 2015; van Deursen and van Dijk 2013). 
Simply providing fast broadband or high-quality hardware and software has not created a 'pipeline to prosperity' (Eynon and Huw in press). Instead, it has exacerbated entrenched inequalities and created new challenges (DiMaggio and Garip 2012; Eynon and Geniets 2016; Warschauer 2003).

Today, these new challenges include the inequalities enacted by 'data practices'. Algorithmic security assessments target specific subgroups, whose applications are systematically denied (Leurs and Shepherd 2017). When statistical models predict which children are at risk of abuse, human experts defer to these computerised risk assessments (Eubanks 2018). Venture capitalists push algorithmic decision-making as the basis for personalised learning; predictive analytics are being proposed that could help to discourage lower-income students 'at risk' of dropping out of university from going in the first place (Watters 2017). 'Digital redlining', i.e., the categorisation of students into classed bodies with differential access to information through regulation, tracking and filtering, actively limits the opportunities of some (mainly working class) students (Gilliard and Culik 2016). A growing body of work on data activism explores ways that existing power relations are being challenged by mobilising data to enhance social justice (Fritsch 2018; Gutiérrez 2018; Kennedy 2018).

In between algorithmic control mechanisms and data justice, an open question remains how those working 'on the ground', developing the personalised learning technologies or advocating for better data practices, describe their data practices. This paper draws on extended ethnographic interviews to ask how actors in educational technology talk about data practices. Although many clearly make token gestures towards equity and social justice, the focus in this paper is specifically on those who voice a deep commitment to data ethics and to increasing equality. How do they express this commitment? How does this aid our understanding of the hopes pinned on technology in the datafied present? 


\section{Concepts and methods}

'Datafication' is understood here as the rendering of myriad forms of information about education, in particular about learning, into 'machine-readable digital data, which can then be subjected to sophisticated forms of processing, calculation, analysis, interpretation, visualisation and circulation' (Williamson 2018, xv).

An ethnographic approach was adopted to explore how edtech organisations working at describe their own approach to digital data. This paper emerges from a study in which openended, ethnographic interviews were conducted with twelve stakeholders in data-based educational technology for schools (K-12) in the USA in 2017, including CEOs and CTOs of successful start-ups, managers at major educational publishing houses (now rebranded as 'learning companies'), and advocates for a better understanding and use of student data. The goal of this paper is not a systematic typology of different data practices, but an in-depth look at three 'rich points'. Rich points, drawing on Agar (2006), are those moments which surprise, confuse or intrigue the ethnographer. As noted above, previous studies have observed the cynicism and market orientation of edtech providers. A similar stance was observed among some interviewees (see Macgilchrist 2017). Rich points emerged as it became clear that three interviewees' references to pedagogical care, ethics and equity were not being made as tokenistic gestures.

However, the goal of this paper is also not to identify straightforward 'good practices' among educational technology providers. Instead, taking an ethnographic sensibility means assuming that data practices will be 'messy' (Lather 2010). The goal is to identify tensions which point to broader issues in contemporary society; to complexify understandings of data practices and the potential effects of datafication by taking a close look at specific cases and engaging with the stories told by the people involved. Although, for instance, digital data 'can' be subjected to sophisticated forms of processing, etc (as Williamson 2018 writes), in practice, 
the use of data is often relatively unsophisticated (Selwyn 2016). The descriptive question for this paper is thus how these individuals express a commitment to ethics and equity. The analytical question is how this complexifies our understanding of the hopes pinned on technology to enable educational equity.

To analyse the interviews, the concept of 'cruel optimism' became relevant. Berlant describes 'cruel optimism' as those moments in which something we desire is actually hindering our ability to attain it (Berlant 2011, 1): Optimistic is the animating, sustaining, energizing belief in 'the good life', and in the struggles and change required to reach this good life: in the case of educational technology, the good life would be the equity and social justice enabled through the use of digital technology. This optimism is cruel when it is tied to fraying fantasies of the good life, e.g. when people remain attached to the fantasies of romantic love, upward mobility or solidarity of political systems despite their fragility (Berlant 2011, 21).

Berlant traces the conditions under which affective attachments to fantasies of the good life remain powerfully attractive, even as they block the satisfactions they seem to offer to individuals and collectives $(2011,13)$. Cruel optimism is a concept for thinking about the 'chaos of the present moment' $(2011,260)$ of ordinary lives 'disorganized' by capitalism in its many contemporary enactments $(2011,8)$ but when catch-all concepts like 'neoliberalism' do not offer enough complexity, nuance or ambivalence (for analyses of cruel optimism in education, see, e.g., Moore and Clarke 2016; Rasmussen 2013; Zembylas 2016).

The following section presents three data stories to illustrate three enactments of cruel optimism in educational data practices: (i) generating data to close the achievement gap, (ii) protecting data to ensure privacy, and (iii) using data to expose inequity. The conclusion reflects on what these stories mean for education in the current phase of edu-technical transformation. 


\section{Data stories}

\section{Data story 1: Generating data to close the achievement gap}

The first data story concerns a for-profit data-driven literacy platform. The website says it 'is built around self-paced and collaborative learning, freeing teachers to truly personalize instruction for individuals and small groups'; 'Lessons are differentiated for each learner's readiness level so teachers can challenge and inspire students with "just right" texts and tasks'. The website cites several independent reports and case studies from schools which demonstrate that students using the platform outperformed students using other literacy approaches: The platform helped students 'achieve an extra year's worth of growth in one school year', achieve '1.5-2.5 average years of grade-level growth when compared to NWEA ${ }^{2}$ grade-level norms', and gain ' 6.29 test-score points above the control group on the NWEA MAP test'. This latter finding is presented as the equivalent of 'closing the achievement growth gap by: $264 \%$ for Low-Income Students, 456\% for Black Students and 749\% for Hispanic Students'.

During an interview, the CEO, Nancy (pseudonym), a former English teacher and then Director of Curriculum and Instruction for approx. 115 schools, refers not to the 'achievement gap' but to the 'opportunity gap'.

B: But the most innovative things are still those very tactical things. Like a teacher being able to give feedback during class time. Most English teachers have never done that because it's really hard to do. Because you've got all these little munchkins running around. You know? So/ I: Yeah. But it's something that's always wanted?

B: But it has tremendous outcomes on the other hand. It's the number one way to close the opportunity gap is to give rapid feedback. It's the number one thing we can do. Doing it during class time is the only way we can actually do it. But it's literally never conceived of as a thing you should be doing during your class time. (interview 2017-03-28_US06_83).

\footnotetext{
${ }^{1}$ To retain the relative anonymity of the interviewees, the sources of descriptions are not provided. All information is from the websites and/or interviews conducted in 2017.

${ }^{2}$ This refers to standardized assessment tools available from the not-for-profit organisation NWEA.
} 
Nancy prioritizes pedagogical practices which provide opportunities. Core practices for fostering student success are everyday tactical innovations like giving rapid feedback during class time. This practice is integrated into the platform's design: The colour-coded data dashboard gives teachers a quick overview. It makes grading faster by automating the reading assessment and by giving a standards-aligned rubric for teachers to assess writing within the platform so that students see the feedback within the class.

Asked how the platform uses data about individual students, Nancy responds: 'I think that that picture not only of what performance levels you've attained, but your growth over time and quite honestly the topics you've been exposed to, that's the real richness' (interview 201703-28_US06_49):

Because, you know, if I said to you what's a main idea, you would be able to tell me the definition as an educated person. If I asked you to read a paragraph on baroque music, you would be able to tell me the main idea of that paragraph. If you know nothing about baroque music you won't be able to tell me what you've read. You'll be able to point out the feature that was the main idea, that would be clear to you. But what those words mean, you may or may not understand. And that's where topical knowledge is actually one of the things that is very uneven. Our assessments [in the USA] are supposed to be generic, but they're not. [...] If you're a student who just got here from Mexico and never heard of the Civil War, it doesn't mean you can't read, it doesn't mean you can't think. It means you've never heard of Abraham Lincoln, you have no idea who the Confederates are. You don't know who won, you don't know/ Like it's just, it's lack of exposure to actual content knowledge that is usually the biggest source of inequity in knowledge. (Interview 201703-28_US06_49-51)

Since assessments in the USA assume a shared nationally specific knowledge base, this content plays a large role in 'inequity in knowledge'. The platform aims to teach students how to identify a text's 'main idea' even if they have not been exposed to the topic, and it aims to expose students to the central topics that are likely to be assessed. In this way, it aims to support students who are often marginalized by the school system to achieve as well as their 
mainstreamed peers. Overall, by offering tools to enact tactical innovations, the platform is designed to function as a 'scaled-up' version of continuous professional development (CPD) for the teachers who use it (interview 2017-03-28_US06_5).

\section{Reflection 1: The cruel optimism of generating data to close the achievement gap}

The optimism seems clear here: the numeric data generated through empirical research show the benefit of using this literacy platform, especially for disadvantaged students; data dashboards support teachers; individual students engage with assessment-relevant content knowledge. The optimism becomes 'cruel' when it involves attachment to the belief that closing an 'achievement gap', and equalizing or levelling the school system, will lead to greater equality across society.

Understanding 'educational equity' as closing the gap on test achievements among subgroups of students (generally minority and nonminority students) has been sharply critiqued by a range of scholars (Noguera and Rios 2012; Milner 2013; Ladson-Billings 2006; Carter and Welner 2013). The metaphor of the achievement gap is often associated with a discourse of individual or community deficit, since it presupposes that it is the student who achieves or does not. The metaphor 'disguises the accumulation of societal and educational exclusions of and prejudices toward historically marginalized students, their families, and their communities that leads to the so-called gaps' (Scheurich et al. 2017, 508f.).

Nancy does not reproduce this deficit discourse. Although the website taps into the discourse of closing the 'achievement growth gap', she consistently refers to opportunities and the 'opportunity gap' (interview 2017-03-28_US06_31, 55, 85). This concept shifts attention from educational outputs (performance) to inputs (resources). It shifts responsibility from the individual to the structural opportunities made available to students who have historically been excluded or disadvantaged by the school system. Nancy prioritizes several systemic 'gaps' which undergird differences in individual test achievement: She talks about teacher quality, 
teacher training and a challenging curriculum (see Irvine 2010, p. xii, cited in Scheurich et al. 2017). These factors are internal to the educational system. However, further entrenched inequalities arguably remain outwith the remit of any edtech company: 'the school funding gap; $[\ldots]$ the wealth and income gap; the employment opportunity gap; the affordable housing gap; the health care gap; the nutrition gap; the school integration gap; and the quality childcare gap' (ibid.).

A relation of cruel optimism appears in the fantasies projected onto personalised learning technologies like this literacy platform. Governments, philanthropists and parents worldwide are channelling hopes and finances into hardware and software which aim to redress the achievement gap. Advocates for a more effective use of educational data aim to give policymakers 'the evidence they need to direct scarce resources in ways that truly work for students' (Data Quality Campaign 2017). When enthusiasm for data-driven technology focuses attention on unachievable fantasies of an equitable good life within contemporary regimes of capital, it diverts attention from other ethical, social, political and economic questions about contemporary education (Rasmussen 2013). Instead, the fantasy of equality is projected onto socio-technical mediators that enable minor interruptions in unjust practices but arguably disable major political or economic transformation (Berlant 2011, 25).

\section{Data story 2: Protecting data to ensure privacy}

The second data story draws from an interview with Amelia (pseudonym), the CEO of a notfor-profit learning platform for mathematics. It describes itself as a comprehensive curriculum for maths, designed to cover the whole school year, replacing the textbook.

I asked whether parents of teachers have raised privacy concerns, given the amount of data required to personalise the individual digital lessons and give teachers an overview of 
students' learning. The question was met with a passionate response highlighting ethics and values.

So, you know, I'm a mom, and, you know, I think about if there was like some app out there collecting information on my children, I would find the server firm and burn it to the ground. So, like, I think the people who are vigilantly protecting children and focused on potentially crazy views on data, I largely agree with them. Right? So, I'm coming with that mind-set of do not touch children's data. Do not profile children. I mean selling children's information is like revolting to consider. But even developing a full profile of an actual child where you can attribute any personal information to that child is/ that's revolting to think about. So I start there, which is that I agree with what might be the kind of left-wing nut jobs who don't want student data pulled together. My head of product lab also agrees. So, she and I just start with that mind-set. (Interview 2017-04-07_US10_79)

Later in the interview as we continued to speak about data and privacy, she critiques her peers in the edtech community who 'whine' about the challenges of encoding privacy into the technology. For her, 'this whole contortion people make around student data privacy interfering with edtech is like just total bullshit' (interview 2017-04-07_US10_85).

That would be like a toy manufacturer being like, "It's so hard not to put chemicals on these toys that we make. This is so hard! We're so upset about these rules." That's disgusting, that's a disgusting mind-set. Your mind-set should be, "My own baby could put this in their mouth. And so I will do my absolute best with like the best intentions in my heart to make this safe." And that is a value, right? (Interview 2017-04-07_US10_87)

The language and specificity here break with the smooth responses of some other interviews, where the interviewees assured me that they of course take data privacy very seriously, and then swiftly moved on to other topics or waited for the next question. Amelia's responses indicates a level of annoyance with this debate (and perhaps with the interviewer's naïve questions) that speaks to a deep commitment to protecting the data generated by the platform to ensure the young users' privacy. 
This ethical commitment translates into the company's business, technical and legal practices. Amelia emphasises several times that complying with legislation and safeguarding data is simply 'the cost of doing business with children' (interview 2017-04-07_US10_85). Her company has no problem showing academic outcomes and personalising learning 'but it is much more tricky and complex'. Problems require more complex solutions, partnering with apps is more complex. 'And we just take that complexity as a cost of doing business' (interview 2017-04-07_US10_85). 'We just take a lot of extra steps. We spend money and effort and we take a lot of extra steps' (interview 2017-04-07_US10_89). The task of edtech companies is, in her view, to take this cost and 'lead on it' (interview 2017-04-07_US10_85).

Leading on it means engaging with the legislation. In other interviews I had heard about instances of company lawyers negotiating with schools or districts to make clear that a data privacy agreement would hinder their ability to work. Occasionally, the lawyers manage to effect changes to the agreements to make them more workable (interview 2017-0317_US01_102). Amelia agreed with these other interviewees that many current privacy laws are not practicable but distanced herself from this practice.

So, we have no interest in like skirting student data, doing the bare minimum, pushing the laws, framing them/ Like a lot of laws make no sense. And clearly the people who wrote them have never even looked at an Excel database. And so what you're sharing when people talk about, "Well, we need to baselines to figure out gains and we need to profile to be able to personalize," that's fair. And a lot of this, a lot of the laws kind of don't make sense. But the thing that we put on top of that is that's fine that the laws don't make sense, but like actually, we agree with where they're trying to get to. Their ultimate goal is dead right. So, basically, we do back bends to follow it and to lead on it. (Interview 2017-0407_US10_79)

Key to this data story are ownership rights. 'So, here's the big idea, here's the most important idea: We don't own that data. It's not ours. It belongs to the school' (interview 2017-0407_US10_97). Almost two million students were using the product at the time of the interview. 
Apart from the case studies on the website, the company releases no information about the schools, districts or states that they are working with (interview 2017-04-07_US10_83). Amelia tells me of funders who say things like: 'Hey we're interested in Michigan. Will you send us all the schools that use your product in Michigan?'. And this edtech provider will say no (interview 2017-04-07_US10_83).

This also means schools maintain control over the future of the data. If a school asks them to delete the entire account, the company will check back: We do a hard delete, nothing will be retrievable, please confirm before we proceed. And if the school confirms, Amelia considers this their 'business obligation' to delete the data. Compare this, she says, to a credit card company, which will certainly not delete your data if you cancel your credit card, because the company owns the data, not the customer. In this sense, and while acknowledging its flaws, she praises the Californian SOPIPA legislation because the 'most important' thing now is moving forward towards school-centred ownership (interview 2017-04-07_US10_10).

Leading on privacy also includes finding technical solutions. Asked about whether certain things are not possible if privacy is engineered into the software in a serious way, which is a view I had heard in previous interviews, she answers, 'I mean you can do anything, right? So, I think it's all about doing things smartly' (interview 2017-04-07_US10_97). She describes, for instance, how they double-blind anonymise the data so that even she herself cannot find the names of individual students. And she disputes those in the edtech field who claim that student data privacy interferes with learning: These are not 'real' scenarios. It does increase the complexity, but: 'If you're really trying to solve that problem, you can solve it' (interview 201704-07_US10_99).

\section{Reflection 2: The cruel optimism of protecting data to ensure privacy}

Four dimensions of society's optimism meet in this data story. First, that values can be translated into ethical socio-technical practice. Second, that other edtech providers (including 
for-profit firms) can also see data privacy as a cost of business. Third, that legislation is moving forward in the right direction, and can safeguard future data practices. Finally, that technical solutions can be found to data-relevant problems. These four together should ensure that the student data generated through edtech are not exploited, that education remains a public good, and that students are not treated primarily as revenue-generating data servants. This optimism becomes cruel precisely because of the sense of possibility it creates for the wider world: that student data not be exploited, and young people not seen as sources of profitable data.

In this story, the school, where young people spend much of their waking lives, is a protected space. However, young people also live, first, within the everyday commercial space of global technology firms whose revenue stems primarily from the legitimated exploitation of user data for advertising. They live, second, within the political space of illicit data-mining and data analysis, flagged by, for instance, the Cambridge Analytica case in which a political consulting firm used profile data from 50 million Facebook users to target users with political campaign messages during the 2016 presidential election in the USA. And, third, young people attend schools within an educational policy space in which 'digital redlining' limits their opportunities to participate actively in public life (Gilliard and Culik 2016).

An optimism which focuses on the use of technology in classrooms, or in schools, neglects how these broader spaces in which public education unfolds are intimately interwoven with technology. This optimism hints at a new dimension of post-democracy (Crouch 2004; Stalder 2015). Crouch (2004) argued that professional politicians, business elites and capitalist economic interests are now making decisions behind closed doors that were previously made with the active participation of ordinary people. The content of history curricula and textbooks, for instance, has been a frequent site of public debate and political contestation (Fuchs and Bock 2018). Today, alongside the political and business elite, the technological elite also increasingly makes decisions that shape public life. In education, no matter how good the 
motives, and how pedagogically well-founded the decisions, it is a post-democratic moment when the ability to make these decisions has shifted from publicly accountable government officials, policy-makers or educators, to developers, programmers, designers and other staff in private edtech organisations. ${ }^{3}$

As I noted above, this is not to criticise the not-for-profit company which designs a far better and more just privacy policy, embedded in a thoughtful pedagogical approach, than many other technology providers. It is, however, to reflect on the cruelty of society's optimism that focussing attention on protecting young people's data (in schools) can repair or resist the commercially-oriented 'datavaillance' (Clarke 1988) in their everyday data-saturated lives. In this data story, ethical data policy and practice may help us survive the constant monitoring of our lives through mainstream technology. Amelia's passion for privacy marks a respite offered in this educational space; but it also unfolds within a broader sociotechnical move towards post-democracy (see Berlant 2011, 117, 122; Stalder 2015).

\section{Data story 3: Using data to expose inequity}

The third data story begins with the ethical challenges of data practices which are not illegal but seem inappropriate. Sena (pseudonym), a staff member of a national non-profit organisation which advocates for effective data use, said that in these situations, her organisation tries to 'get people more involved in decision-making and understanding why data is being used for different purposes' (interview 2017-03-21_US03_156). The goal is for people to be more informed, to appreciate the uses that benefit them, and to have a platform to disagree with those uses that seem detrimental. When I ask who tends to get involved in these discussions, assuming it may be higher income families who have more time an financial

\footnotetext{
${ }^{3}$ Projects such as the Schulbuch-O-Mat propose open source alternatives which prioritise public participation, collective deliberation and community control over the algorithms for adaptive processes (www.schulbuch-o-mat.de).
} 
resources to spare, she replies:

Sometimes the biggest champions are actually lower income families, because they know that they've been receiving inequitable educational opportunities. So they can/ If they are sure that the data's being used appropriately, not to sort of punish their child, but/ they can often be real champions. Because they see it as a way to expose inequities. (Interview 2017-03-21_US03_158)

To my question about whether data have actually been used to address entrenched inequalities, Sena says 'Hopefully': She sees good data practices being developed at state level that uncover inequities, but there are few systems in place that lead to significant changes in situated practice. In one example she mentions, the school system in Washington, D.C., analysed its data to create an equity report card for each school. They found that schools were giving harsher discipline to African American students than to white students. Those in charge looked at the data, formed a task force and are working to make a change. 'But', she added, 'that's more of an outlier than it hopefully will be' (interview 2017-03-21_US03_162). Reacting to my comment that 'there could be a lot of use of data for that [sort of change], but it has to be pushed by somebody, right?', she reflected:

Yeah. Yeah, it's always hard when the data shows something bad or difficult. That's where it's really hard to take action. Because/ And I think that's why sometimes people are hesitant to use data, because if you don't see something, it's not a problem. But once you see it, you might have to do something about it. (Interview 2017-03-21_US03_170)

In this data story, people hesitate to use data, not because it is impossible to address structural inequalities, but because it is too possible, albeit incredibly difficult, to take action.

\section{Reflection 3: The cruel optimism of using data to expose inequity}

In this data story, the visibility of data has an ontological function: it brings problems into existence. As Žižek (2014) argues in another context, we 'didn't really learn anything from 
WikiLeaks we didn't already presume to be true - but it is one thing to know it in general and another to get concrete data'. The data make something a problem that requires action. They become toxic (Berlant 2011, 24). Optimistic is the belief that data can be used to expose inequality and bring about change. The story identifies 'forms of data, data tools and data techniques' that are being used 'to possibly empower otherwise sub-ordinated groups' (Selwyn $2016,66)$. But this optimism can seem cruel when the responsibility is placed on 'otherwise subordinated groups' or individuals to do the exposing.

It is widely recognised that some students are treated more harshly than others. The apparent objectivity and indisputability of quantification now produces inequality and racism as problems for observers and stakeholders who did not previously feel an obligation to act (see Prinsloo and Slade 2017). At the same time, these are human stories. It takes families or individuals in government offices to use data in ways which expose inequalities. This equality aspect of rendering data actionable is not encoded into the software. Human decision-making is overlaid on the machine-readable data. Using data becomes an act that 'create[s] new modes of sense perception and induce[s] novel forms of political subjectivity' (Rancière 2004, 9; see also Williamson 2016).

In this data story, using data to expose inequity extends participation in the governing of education. Families are armed with politicised data visualizations of their experience of inequitable educational opportunities. However, this individualises the responsibility to become informed and expose injustice. Given the volumes of investor capital that flow towards the design and implementation of data technologies compared to the resources for interventions - even those that are only ameliatory - at ground level, this becomes a relation of cruel optimism. The visibility of data implies an obligation for officials to act. It operates as a technology of subjectivation of individual actors, creating activist citizens. But it also 
establishes new norms (of individual responsibility) against which parents or staff can evaluate themselves, and potentially find themselves failing, worn out and frustrated.

\section{Concluding thoughts}

Overall, the paper aimed to illustrate the workings of optimistic attachments in education, as the 'sustaining inclination to return to the scene of the fantasy that enables you to think that this time, nearness to this thing, will help you or a world to become different in just the right way' (Berlant 2011, 2, italics in original). The data stories point to the constitutive paradoxes of education which are 'sticky' and cannot be cleaned away. The stories of generating data, protecting data and using data show hope for change. They also show how the fantasy of equality is projected onto a socio-technical mediator (a personalised literacy platform, data privacy practices, an active parent armed with data visualisations) which enables a small interruption in inequality, but also blocks attention to the weakening of the fantasy of an equitable life in today's increasingly post-democratic world.

The three stories reflect on the relations of cruel optimism across education today. The stories highlight a selection of actors that are not only paying lip service to goals of equality, justice, participation. At the same time, their optimism for a better future through edu-technical interventions (whether for-profit or non-profit) is intimately entangled with today's predominant global economic structure. The optimism is shared by many of those making policy decisions on what to fund, who to support, which kinds of data infrastructures, technologies and practices to push forward. When hardware and software are being financed as the means to close the achievement gap, protect privacy and expose inequalities, this often passionate attachment to technological solutions blocks interventions in historically rooted, structural inequalities.

But at the same time, these stories highlight spaces in which pedagogical relationships, care and solidarity are made more relevant than in many other spaces dominated by data 
technologies. The belief that education (or edtech) can change socio-economic inequalities is an 'animating, sustaining fantasy', indicative of the 'exhausting pragmatics' of the messy, hyperconnected, always-on world of today (Berlant 2011, 261). Even if justice is impossible through education (see Rasmussen 2013), a cruelly optimistic education which values equality as a utopian goal makes school more bearable for its users than educational technology that place profitability before all other values. This suggests that optimism is necessary to survive the impasse of educating in the world today, even if it cannot fix the problems of inequality. The concept of 'cruel optimism' helps us - at least, that is the optimism of this article - to think about the fragile fantasies involved in 'thinking otherwise' about the datafied present, while also remembering that cruel optimism 'is better than no optimism at all' (Berlant 2011, 16).

\section{Disclosure statement}

No potential conflict of interest was reported by the author.

\section{Notes on contributor}

Felicitas Macgilchrist is Head of the 'Media|Transformation' department at the Georg Eckert Institute of International Textbook Studies, Braunschweig, and Professor of Media Research at the University of Goettingen, Germany. Her current research draws on ethnography, discourse studies and cultural theory to explore the socio-political implications of educational technology. ORCID: http://orcid.org/0000-0002-2828-4127

\section{References}

Agar, Michael. 2006. "An ethnography by any other name." Forum: Qualitative Social Research 7 (4):Art 36.

Berlant, Lauren. 2011. Cruel Optimism. Durham: Duke University Press.

Biesta, Gert. 1998. "Say You Want a Revolution...Suggestions for the Impossible Future of Critical Pedagogy." Educational Theory 48 (4):499-510. 
Carter, Prudence, L., and Henry Welner. 2013. Closing the Opportunity Gap: What America Must Do to Give Every Child an Even Chance. Oxford: Oxford University Press.

Clarke, Roger. 1988. "Information Technology and Dataveillance." Accessed 15 March 2018. http://www.rogerclarke.com/DV/CACM88.html.

Crouch, Colin. 2004. Post-Democracy. Cambridge: Polity.

Data Quality Campaign. "DQC Fact Sheet." Accessed 15 March 2018. https://2pido73em67o3eytaq1cp8au-wpengine.netdna-ssl.com/wpcontent/uploads/2016/03/DQC-Fact-Sheet-2017-08302017.pdf.

DiMaggio, Paul, and Filiz Garip. 2012. Network Effects and Social Inequality. Annual Review of Sociology 38 (1):93-118.

European Commission. Digital Agenda for Europe 2014. Available from http://europa.eu/pol/index_en.htm http://europa.eu/!bY34KD.

Eubanks, Virginia. 2018. Automating Inequality: How High-Tech Tools Profile, Police, and Punish the Poor: St. Martin's Press.

Eynon, Rebecca, and Anne Geniets. 2016. The digital skills paradox: how do digitally excluded youth develop skills to use the internet? Learning, Media and Technology 41 (3):463-479. doi: $10.1080 / 17439884.2014 .1002845$

Eynon, Rebecca, and Davies Huw. in press. Is digital upskilling the next generation our 'pipeline to prosperity'? New Media and Society.

Fritsch, Katrin. 2018. Towards an Emancipatory Understanding of Widespread Datafication, Accessed 1 September 2018. http://dx.doi.org/10.2139/ssrn.3122269

Fuchs, Eckhardt, and Annekatrin Bock. 2018. Palgrave Handbook of Textbook Studies. London: Palgrave. 
Gilliard, Chris, and Hugh Culik. 2017. "Digital Redlining, Access, and Privacy." Accessed 28 September 2017. https://www.commonsense.org/education/privacy/blog/digital-redliningaccess-privacy.

Gutiérrez, Miren. 2018. Data Activism and Social Change. London: Palgrave.

Irvine, J.J. 2010. "Foreword." In Culture, Curriculum, and Identity in Education, edited by H. Richard Milner. New York: Palgrave Macmillan.

ITU. 2017a. Fast-forward progress: leveraging tech to achieve the global goals. Geneva (Switzerland), International Telecommunication Union. Accessed 3 September 2018. http://www.itu.int/en/sustainableworld/Pages/report-hlpf-2017.aspx.

ITU. 2017b. Measuring the Information Society Report. Geneva (Switzerland), International Telecommunication Union. Accessed 1 September 2018. http://www.itu.int/en/ITUD/Statistics/Documents/facts/ICTFactsFigures2017.pdf.

Kennedy, Helen. 2018. Living with Data: Aligning Data Studies and Data Activism Through a Focus on Everyday Experiences of Datafication. Krisis: Journal for Contemporary Philosophy 1:18-30.

Ladson-Billings, Gloria. 2006. "From the achievement gap to the education debt: Understanding achievement in U.S. schools." Educational Researcher 35 (7):3-12. Lather, Patti. 2010. Engaging Science Policy: From the Side of the Messy. New York: Peter Lang.

Leurs, Koen, and Tamara Shepherd. 2017. Datafication and discrimination. In The Datafied Society, edited by M. T. Schäfer and K. van Es. Amsterdam: Amsterdam University Press. Macgilchrist, Felicitas. 2017. Backstaging the teacher: On learner-driven, school-driven and data-driven change in educational technology discourse. Culture-Society-Education 12 (2):83103. 
Milner, H. Richard. 2013. "Rethinking Achievement Gap Talk in Urban Education." Urban Education 48 (1):3-8. doi: 10.1177/0042085912470417.

Moore, Alex, and Matthew Clarke. 2016. "'Cruel optimism': teacher attachment to professionalism in an era of performativity." Journal of Education Policy 31 (5):666-77. doi: 10.1080/02680939.2016.1160293.

Noguera, Pedro, and Victor Rios. 2012. "Reframing the Achievement Gap." Contexts 11 (4):810.

Prinsloo, Paul, and Sharon Slade. 2017. An elephant in the learning analytics room: the obligation to act. Paper presented at the LAK '17 Proceedings of the Seventh International Learning Analytics \& Knowledge Conference, ACM, New York, NY.

Rancière, Jacques. 2004. The Politics of Aesthetics: The Distribution of the Sensible. London: Continuum.

Rasmussen, Mary Lou. 2013. "'Cruel Optimism' and Contemporary Australian Critical Theory in Educational Research." Educational Philosophy and Theory 47 (2):192-206. doi: 10.1080/00131857.2013.793929.

Robinson, Laura, Shelia R. Cotten, Hiroshi Ono, Anabel Quan-Haase, Gustavo Mesch, Wenhong Chen, Jeremy Schulz, Timothy M. Hale, and Michael J. Stern. 2015. Digital inequalities and why they matter. Information, Communication \& Society 18 (5):569-582.

Scheurich, James Joseph, Vicki L Bonds, Jada A Phelps-Moultrie, Brandon J Currie, Troy A Crayton, Alycia M Elfreich, Catherine D Bhathena, Tiffany S Kyser, and Nathaniel A Williams. 2017. "An initial exploration of a community-based framework for educational equity with explicated exemplars." Race, ethnicity and education 20 (4):508-26.

Selwyn, Neil. 2016. "'There's so much data': Exploring the realities of data-based school governance." European Educational Research Journal 15 (1):54-68.

Stalder, Felix. 2015. Kultur der Digitalität. Berlin: Suhrkamp. 
van Deursen, Alexander J. A. M., and Jan A. G. M. van Dijk. 2013. The digital divide shifts to differences in usage. New Media \& Society 16 (3):507-526.

Warschauer, Mark. 2003. Technology and Social Inclusion: Rethinking the Digital Divide. Cambridge, MA: MIT Press.

Watters, Audrey. 2017. "The Weaponization of Education Data." Accessed 1 September 2018. https://hackeducation.com/2017/12/11/top-ed-tech-trends-weaponized-data.

Williamson, Ben. 2018. Big Data and Education. London: Sage.

Working Group on Education. Digital skills for life and work 2017. Available from http://unesdoc.unesco.org/images/0025/002590/259013e.pdf.

Zembylas, Michalinos. 2016. "Political depression, cruel optimism and pedagogies of reparation: questions of criticality and affect in human rights education." Critical Studies in Education 59 (1):1-17. doi: 10.1080/17508487.2016.1176065.

Žižek, Slavoj. 2014. "How WikiLeaks opened our eyes to the illusion of freedom " The Guardian, 19 June. 